
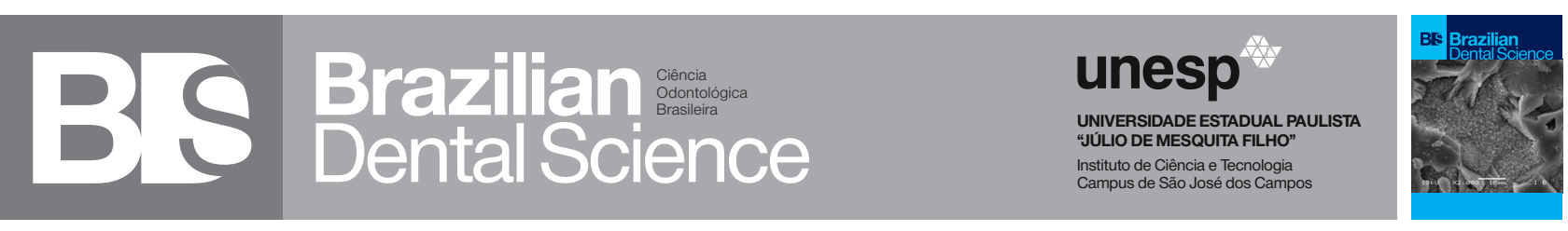

\title{
The influence of early bisphosphonate treatment in bone reconstruction on craniofacial radiographic bone density
}

\author{
A influência do tratamento com bisfosfonatos na densidade óssea em área de reconstrução óssea craniofacial
}

Rafael Zancan MOBILE ${ }^{1,2}$, Lucas de Oliveira AZEVEDO ${ }^{1}$, Shaiene GOMES ${ }^{1}$, Tatiana Miranda DELIBERADOR ${ }^{1}$, Allan Fernando GIOVANINI $^{1}$, Melissa Rodrigues de ARAUJO ${ }^{2}$

1 - Universidade Positivo - Curitiba - PR - Brazil.

2 - Universidade Federal do Paraná, Stomatology Department - Curitiba - PR - Brazil.

\section{ABSTRACT}

Objective: To evaluate the effects of alendronate (AL), a bisphosphonate, on visual bone density by means of a radiographic analysis. Material and methods: Sixty-two Wistar rats were divided into four groups: Group AA (AL with autogenous graft); group AW (AL without autogenous graft) both receiving $\mathrm{AL}$ on alternate days for 4 weeks before surgery; control group CA (with autogenous graft); group CW (without autogenous graft) both receiving saline solution before surgery. Experimental periods of evaluation were 2 weeks and 4 weeks postsurgery. Conventional and digital radiographs were obtained, and a 5-point grading system (score) was used to assess visual radiographic bone density. Results: There were no statistical differences between CA and AA groups at 2 and 4 weeks. The AA group had a higher mean score of bone density than the CW and AW groups at 2 weeks $(P<0.05)$. The CA and AA groups had higher scores of bone density than the CW and AW groups at 4 weeks (P $<0.05)$. Conclusions: Treatment with AL did not affect radiographic bone density at 2 and 4 weeks after surgery. The presence of an autograft resulted in higher scores of bone density.

\section{KEYWORDS}

Bisphosphonates; Radiography; Bone density; Rats.

\section{RESUMO}

Objetivo: Avaliar os efeitos do alendronato (AL), um bisfosfonato, na densidade óssea através de uma análise radiográfica. Material e métodos: Sessenta e dois ratos Wistar foram divididos em quatro grupos: Grupo AA (AL com enxerto ósseo autógeno); grupo AW (AL sem enxerto ósseo autógeno); ambos receberam AL em dias alternados durante 4 semanas antes da cirurgia; grupo controle CA (com enxerto ósseo autógeno); grupo CW (sem enxerto ósseo autógeno) ambos receberam solução salina antes da cirurgia. Os tempos experimentais de avaliação foram 2 e 4 semanas após a cirurgia. Radiografias convencionais e digitais foram realizadas, e um sistema de escore de 5 pontos foi utilizado para avaliar a densidade óssea radiográfica visualmente. Resultados: Não houve diferença estatisticamente significativa entre os grupos CA e AA em 2 e 4 semanas. $O$ grupo AA apresentou maior escore de densidade óssea do que os grupos CW e AW em 2 semanas ( $\mathrm{p}<$ 0.05). Os grupos CA e AA apresentaram maior escore de densidade óssea do que os grupos AW e CW em 4 semanas $(p<0.05)$. Conclusões: $O$ tratamento com AL não interferiu na densidade óssea radiográfica em 2 e 4 semanas após cirurgia. A presença do enxerto resultou em maior escore de densidade óssea.

\section{PALAVRAS-CHAVE}

Bisfosfonados; Radiografia; densidade óssea; ratos. 


\section{INTRODUCTION}

$\mathrm{B}$ isphosphonates (BPs) are a class of drugs highly effective in the treatment of various bone diseases, such as osteoporosis, Paget disease and bone metastasis. These compounds are analogs of inorganic pyrophosphate, an endogenous regulator of bone mineralization. Among the BPs, alendronate (AL) is one of the most commonly used drugs for the treatment of bone disorders $[1,2]$. There is still some controversy in the literature as to the dosage and duration of BPs required to maximize the effectiveness of these drugs in bone remodeling [3]. Many studies have demonstrated bone preservation and maintenance with the use of BPs [4], but it is also known that longterm therapy may impair bone strength, inadvertently altering bone turnover and eventually causing osteonecrosis of the jaw, micro damage and even pathologic fractures [5].

BPs may alter bone turnover, either by a direct action on the catabolic activity induced by osteoclasts or increase the proliferation and osteoblast maturation and inhibit their apoptosis suggesting an anabolic effect mediated by osteoblasts could be attributed to BPs [3].

Several experimental studies evaluated bone healing in surgical defects by assigning scores for varying levels of bone density determined by quantitative image analysis $[6,7]$.

Using radiographic analysis in a critical size defect model, we evaluated if low doses of an early (pre-operative) systemically administered BP would influence physiological bone repair with and without bone grafting.

\section{MATERIAL \& METHODS}

Sixty-two Wistar male rats (Rattus norvegicus albinus) weighing approximately
$350 \mathrm{~g}$ and approximately 150 days old were used in this in vivo experimental study. The rats were randomly divided into four groups: Group AA (AL with autogenous graft); group AW (AL without autogenous graft) both received subcutaneous injections of alendronate sodium ( $50 \mu \mathrm{g} / \mathrm{kg}$ body weight) [8] on alternate days for the 4 weeks before surgery; control group CA (with autogenous graft); group CW (without autogenous graft) both receiving saline solution 4 weeks before surgery to reproduce the stress generated by AL injection. The control groups (CA and CW) received saline solution via subcutaneous injection on alternate days for four weeks before surgery to reproduce the stress generated by AL injection [8]. The animals were housed during the experimental period in optimal temperature and hygiene conditions, with food and water ad libitum and a lightdark cycle of $12 \mathrm{~h}$. The study was approved by the Institutional Animal Ethics committee (protocol 182).

\section{Surgical procedure}

The rats were sedated with oxygen and isoflurane (Cristália, Itapira, SP, Brazil) and subsequently anesthetized by intramuscular injection in the posterior thigh with xylazine $2.3 \mathrm{~g}(0.52 \mathrm{mg} / \mathrm{kg})$ (Vetbrands, Paulinia, SP, Brazil) and ketamine $1.16 \mathrm{~g}$ (1.04 mg/kg) (Vetbrands, Paulinia, SP,Brazil). Anesthesia was maintained by vaporization of isoflurane (Cristália, Itapira, SP, Brazil) by facial mask when needed. An anteroposterior linear incision was made through the scalp and underlying periosteum, and a full-thickness flap was elevated to expose the parietal bone. A critical-size defect was created on the midsagittal suture using a trephine bur with a 5-mm diameter under abundant irrigation with sterile saline. After the removal of the outer and inner cortical tables of the parietal bone, the dura mater was kept intact. The removed bone was milled (Kopp ${ }^{\circledR}$, Curitiba, Brazil) and 
used to fill the defects of groups CA and AA. The defects of groups CW and AW were filled with blood clot only. Flaps were repositioned and sutured with nylon 3-0 (Ethicon ${ }^{\circledR}$, Johnson \& Johnson, São Paulo, SP, Brazil). Immediately after surgery, an intramuscular injection of 0.1 $\mathrm{mL}$ morphine $(1 \mathrm{mg} / \mathrm{mL})$ (Dimorf ${ }^{\circledR}$, Cristália, Itapira, Brazil) was given for analgesia, and a paracetamol solution (1.5 mg / $100 \mathrm{~g}$ body weight) (Medley ${ }^{\circledR}$, Campinas, Brazil) was given three times a day for three days.

Rats were euthanized at either 2 and 4 weeks after surgery by $\mathrm{CO} 2$ inhalation [9]. The calvaria were removed, rinsed in water, and placed in $10 \%$ buffered formalin for 48 h. After this period, digital and conventional radiographs were taken.

\section{Radiographic Assessment}

Radiographs of each specimen were taken with a calibrated x-ray unit (Dabi Atlante $^{\circledR}$, Ribeirão Preto, Brazil) at $70 \mathrm{kVp}, 7$ $\mathrm{mA}$, and exposure times of $0.20 \mathrm{~s}$ and $0.12 \mathrm{~s}$ for conventional and digital methods, respectively. An object focal distance of $20 \mathrm{~cm}$ was adopted for both methods. For the conventional method, Ultra-speed film (Kodak ${ }^{\circledR}$, Rochester, NY) was used. The digital method was performed with a $3 \mathrm{~cm} \times 4 \mathrm{~cm}$ Kodak RVG $5100^{\circledR}$ sensor $\left(K{ }^{3}{ }^{\circledR}{ }^{\circledR}\right.$, Rochester, NY). The conventional radiographs were developed manually using the time-temperature method. Digital images were saved in TIFF ( 8 bit) format without compression. All digital and conventional radiographs were analyzed by two pre-instructed examiners who determined the extent of radiopacity in the defect area as an indicator of bone repair. A 5-point grading system (score) was used to analyze visual radiographic bone density and quantify bone formation in the defect area by means of radiopacity [10], as follows:
Score of 1: no bone formation, absence of radiopacity within the defect area:

Score of 2: up to $25 \%$ of the defect area was filled with bone;

Score of 3 : between $25 \%$ and $50 \%$ of the defect area was filled with bone;

Score of 4 : between $50 \%$ and $75 \%$ of the defect area was filled with bone; and

Score of 5: between $75 \%$ and $100 \%$ of the defect area was filled with bone.

The scores obtained from individual examiners were analyzed statistically.

\section{Statistical analysis}

Statistical analysis was performed with SPSS software, Version 20.0 (SSPS, Chicago, IL, USA). The data were analyzed using nonparametric tests (Kruskal-Wallis and MannWhitney). To assess agreement between the two examiners, a Kappa test was applied; P < 0.05 was considered statistically significant.

\section{RESULTS}

62 conventional and 62 digital radiographs were evaluated. The analysis of interobserver variability showed a moderate agreement in digital radiograph analysis $(0.53,95 \% \mathrm{CI})$ and a substantial agreement in conventional radiograph analysis $(0.69 ; 95 \%$ CI) $(\mathrm{P}<0.001)$ (Kappa test).

The scores assigned to the conventional radiographs were analyzed statistically, because there was greater agreement for this method, as indicated by the mean of the scores assessed by the two examiners. The numbers of rats in each group, the mean, median, minimum, and maximum scores for all groups are shown in Table 1. 
Table 1 - Mean, median, minimum and maximum radiographic scores at 2 and 4 weeks in the studied groups.

\begin{tabular}{|c|c|c|c|c|c|c|c|c|}
\hline Exp Period & Groups & $\mathbf{N}$ & Mean & Median & Min. & Max. & SD & $\mathrm{P}^{*}$ value \\
\hline \multirow{5}{*}{2 weeks } & CA & 8 & 29 & 2.8 & 2.0 & 5.0 & 1.1 & \\
\hline & CW & 5 & 2.3 & 2.5 & 1.0 & 3.0 & 0.8 & 0.016 \\
\hline & AA & 8 & 3.8 & 3.8 & 2.0 & 5.0 & 1.0 & \\
\hline & AW & 9 & 2.3 & 2.0 & 2.0 & 4.0 & 0.7 & \\
\hline & $\mathrm{CA}$ & 8 & 4.6 & 4.8 & 3.0 & 5.0 & 0.6 & \\
\hline \multirow{3}{*}{4 weeks } & CW & 8 & 2.8 & 2.8 & 2.0 & 4.0 & 0.8 & $<0.001$ \\
\hline & $\mathrm{AA}$ & 7 & 3.9 & 4.0 & 3.0 & 5.0 & 0.9 & \\
\hline & AW & 9 & 2.0 & 2.0 & 2.0 & 2.0 & 0.0 & \\
\hline
\end{tabular}

Exp Period= experimental period; $\mathrm{N}=$ number of radiographs in each group; Min=minimum; $\mathrm{Max}=$ maximum; $\mathrm{SD}=$ standard deviation . AA: AL with autogenous graft; AW: AL without autogenous graft; CA: control group with autogenous graft; CW: control group without autogenous graft. $\left(^{*}\right)$ Kruskal-Wallis nonparametric test; $P<0.05$.

The mean radiographic scores of all groups were compared for the two experimental periods ( 2 and 4 weeks), and the results are shown in Table 2 .

Table 2 - Comparison of mean radiographic scores of all groups at 2 and 4 weeks.

\begin{tabular}{|c|c|c|}
\hline Exp Period & Groups in comparison & $P^{*}$ value \\
\hline \multirow[b]{3}{*}{2 weeks } & $\mathrm{CAxCW}$ & 0.362 \\
\hline & CAXAA & 0.062 \\
\hline & CAxAW & 0.124 \\
\hline \multirow{9}{*}{4 weeks } & CWXAA & 0.014 \\
\hline & CW $x$ AW & 0.666 \\
\hline & AAxAW & 0.001 \\
\hline & CAxCW & $<0.001$ \\
\hline & CAXAA & 0.093 \\
\hline & CAxAW & $<0.001$ \\
\hline & CWXAA & 0.001 \\
\hline & CW xAW & 0.006 \\
\hline & AAXAW & $<0.001$ \\
\hline
\end{tabular}

Exp Period = experimental period; $A A$ : $A L$ with autogenous graft; AW: AL without autogenous graft; (CA) control group with autogenous graft; CW: control group without autogenous graft. (*) Kruskal-Wallis nonparametric test; $\mathrm{P}<0.05$.

\section{DISCUSSION}

An increased interest in the effects of BPs on trabecular architecture and bone repair has been reported recently [11,12]. Bone turnover is determined by the balance between osteoclastic bone resorption (a catabolic response) and osteoblastic bone formation (an anabolic response). BP treatment may affect both these mechanisms by inhibiting osteoclastic activity and having an anabolic effect on osteoblasts [13].

We hypothesized whether the early events of a systemically administered AL would interfere in bone healing of critical size defects in a radiographic evaluation.

There was no difference in bone repair in AL treatment when compared to control groups (saline solution injection). Camati et al. [9] did not observe improvements in cranial bone matrix deposition with systemic application of $\mathrm{AL}$ at a dose of $0.01 \mathrm{mg} / \mathrm{kg}$. However, they observed expression of IGF1, Osteopontin and a slight marking of IGF2 in animals receiving autogenous bone in the wound healing process. Yaffe et al. [15] also suggested that $\mathrm{AL}$ is ineffective during the bone formation phase, but effective in inhibiting bone loss. The administration of BP after autogenous bone graft onto a rat calvarium decreased resorption of the grafted bone [16]. 
The period over which AL is administered and the type of BP might influence its effects on bone repair. Our protocol used AL only before the surgical defect was created (4 weeks before surgery, alternate days), and radiographic bone density was analyzed at 2 and 4 weeks after surgery. Yaffe et al. [15] administered AL ( $0.25 \mathrm{mg} / \mathrm{kg}$ body weight) at 1,2 , and 3 weeks (early bone formation phase) to one group and at 3,4 , and 5 weeks to another group after the creation of a surgical defect. They observed a $70 \%$ and a $166 \%$ increase in bone mass and visual bone density at 6 and 10 weeks post surgery, respectively, when AL injection was given at 3, 4 and 5 weeks. Therefore, in our study, the absence of a difference in bone repair could be due to $\mathrm{AL}$ administration prior to surgery rather than after and/or to the possibility that 4 weeks post surgery is an insufficient time for any difference to be visualized in radiographic analysis. Tatli et al. [17] demonstrated a temporary delay in physiological bone remodeling using a single dose of ZA. They showed that ZA increased $\mathrm{BMC}$ and made the microarchitecture of the mandibular condyle more compact. Myoung et al. [16] initiated BP treatment 2 weeks after performing a cranial bone graft and conducted their evaluation after 4,6 , and 8 weeks. Bone resorption was inhibited in $\mathrm{BF}$ groups, whereas groups that received saline solution showed massive bone resorption and an irregular margin of grafted bone. They also found a significant increase in osteocalcin at 6 and 8 weeks, which indicates its potential to stimulate bone formation. Altundal et al. [12] did not observe any difference in the number of osteoblasts when comparing a 2-week AL group to a 4-week saline group. They suggest that $\mathrm{AL}$ initially decreases bone resorption during the resorptive phase by inhibiting the recruitment and activation of osteoclasts.

If $\mathrm{BP}$ treatment reduces bone turnover, a period greater than 4 weeks may be required for sufficient mineralization of existing bone to occur and to demonstrate an increase in bone density on radiographs.
The radiographic analysis performed in our study did not detect differences in bone formation between $\mathrm{AL}$ and control groups. However, Giro et al. [8] evaluated the influence of estrogen deficiency and AL therapy by means of radiographic analysis and demonstrated an increase in BMD and bone mass because of a decrease in bone remodeling. BPs act as bone formation stimulators and potentially have a beneficial influence on the bone formation process. They might provide benefits not only through an anti-resorptive effect but also through an effect on bone formation [12]. Myoung et al. [16] observed reduced osteoclastic activity and reduced resorption of the grafted bone in BP treated groups. However, they observed that grafted bone was also actively resorbed in the saline treated groups. Since histology is the gold standard by which bone resorption is detected, it is possible that the radiographs we performed did not have sufficient sensitivity to allow detection of any difference in radiopacity (bone density).

We used a low dose of AL in order to investigate if early BP treatment would modify bone repair as assessed by changes in bone density on radiographic analysis. However, there were no differences in bone density between the AL group and the saline group. It has been previously demonstrated that lower concentrations of BPs have a beneficial effect on osteoblast viability and function [18]. Very low doses of BP were demonstrated to increase parameters of bone formation on histological analysis $[19,20]$. Treatment with BP also led to the retention of trabeculae that act as a scaffold for more bone to be deposited [21]. Altundal et al. [12] reported a positive effect of BP on the induction of osteoblastic activity using AL (0.5 $\mathrm{mg} / \mathrm{kg}$ body weight) for 3 weeks. Nevertheless, the positive effect of $\mathrm{BP}$ on bone healing is not a consensus [22].

The goal of dental radiology is to make an accurate diagnosis using the most effective imaging modality with the lowest radiation possible [23]. To assess conventional and digital radiographs, many tools can be used, 
such as image subtraction, pixel evaluation, and subjective evaluation, the latter of which was our choice. We found the more accurate method to be conventional radiography. Ashwinirani et al. [23] indicated that both conventional and digital radiographic methods underestimate bone loss. However, digital radiography is superior to conventional radiography for the detection of interdental bone loss because less time and radiation exposure are required to obtain the same diagnostic information. Conventional and digital radiographs are some of the most widely used methods, but both have a limited role in the precise measurement of bone repair.

The optimal dose of AL, as well as its effect on ectopic bone graft resorption as determined by conventional radiographic analysis, was tested by Kawata et al. [24]. The grafted bone disappeared in the control group (grated bone immersed in saline solution) after 5 weeks post-surgery. In the treated group, AL (0.15 mg) was also injected 5 weeks after transplantation. On radiographic analysis, the bone volume was higher in the mice treated with 10-4 M AL than in those treated with 10-6 M AL, indicating a tendency toward a dosedependent increase, but the difference was not statistically significant. Eight and 9 weeks following ectopic bone graft transplantation, the decreased area of bone was less in all the 10-4 M AL injected/AL-immersed groups than in the 10-4M non-injected/AL-immersed group. $\mathrm{AL}$ at concentrations of 10-4 $\mathrm{M}$ and 10-6 M inhibit resorption of ectopic bone graft, which was clearly present 5 weeks after surgery. We used conventional radiographic analysis, as Kawata et al. [24] did, to evaluate autogenous bone grafts, and this tendency to inhibit bone resorption was not observed in our study at 2 and 4 weeks post surgery.

Radiographic analysis is limited in its sensitivity with respect to the detection of changes in bone density that reflect bone resorption or deposition. There are many other methods, such as histology, histomorphometric evaluations, and computed tomography, that are more sensitive in the assessment and quantification of bone repair $[7,8,11,17,22]$. However, digital and conventional radiography are very common techniques and readily available to most clinicians.

Treatment with AL itself did not interfere with bone repair evaluated by either conventional or digital radiographs. Differences in the duration of treatment and the doses used should be tested in order to more fully evaluate the benefits of BP on bone formation.

Suppression of bone turnover by BPs prevents bone loss and increases tissue mineralization; however, this was not observed in our radiographic study. The presence of the autogenous graft was the primary factor that contributed to a higher bone density score.

\section{CONCLUSION}

Low doses of a systemically administered BP did not influence physiological bone repair, as determined by radiographic analysis, either with or without bone grafting in a critical size defect model. Short and early (preoperative) treatment with low doses of AL did not have an effect on radiographic bone density at 2 and 4 weeks post-surgery.

\section{REFERENCES}

1. Chaudhry AN, Ruggiero SL. Osteonecrosis and bisphosphonates in oral and maxillofacial surgery. Oral Maxillofac Surg Clin North Am. 2007; 19(2):199-206. doi:10.1016/j.coms.2007.01.005

2. Nishitani K, Shirai T, Kobayashi M, Kuroki H, Azuma Y,Nakagawa Y, etal. Positive effect of alendronate on subchondral bone healing and subsequent cartilage repair in a rabbit osteochondral defect model. Am J Sports Med. 2009; 37(1):139S-47S. doi: 10.1177/0363546509350984.

3. Toker $\mathrm{H}, \mathrm{Ozdemir} \mathrm{H}, \mathrm{Ozer} \mathrm{H}$, Eren $\mathrm{K}$. Alendronate enhances osseous healing in a rat calvarial defect model. Arch Oral Biol. 2012 Nov;57(11):1545-50. doi:101016/j. archoralbio.2012.06.013.

4. Borah B, RitmanEL, Dufresne TE, Jorgensen SM, Liu S, Sacha J, etal. The effect of risedronate on bone mineralization as measured by micro-computed tomography with synchrotron radiation: correlation to histomorphometric indices of turnover.Bone. 2005;37(1):1-9. doi: 10.1016/j.bone.2005.03.017

5. Mashiba T,Mori S, Burr DB, Komatsubara S, Cao Y,Manabe T, etal. The effects of suppressed bone remodeling by bisphosphonates on microdamage accumulation and degree of mineralization in the cortical bone of dog rib. $\mathrm{J}$ Bone Miner Metab. 2005;23:36-42. 
6. Betti LV, Bramante CM, Cestari TM, Granjeiro JM, Garcia RB, de Moraes IG, et al Repair of rabbit femur defects with organic bovine bone cancellous block or cortical granules. Int J Oral Maxillofac Implants. 2011;26(6):1167-75.

7. Célio-Mariano R, de Melo WM, Carneiro-Avelino C. Comparative radiographic evaluation of alveolar bone healing associated with autologous platelet-rich plasma after impacted mandibular third molar surgery. J Oral Maxillofac Surg. 2012; 70(1):19-24.

8. Giro G, Gonçalves D, Sakakura CE, Pereira RM, Marcantonio Júnior E, Orrico SR. Influence of estrogen deficiency and its treatment with alendronate and estrogen on bone density around osseointegrated implants: radiographic study in female rats. Oral Surg Oral Med Oral Pathol Oral Radiol Endod. 2008:105(2):162-7.

9. Camati PR, Giovanini AF, Peixoto HEM, Schuanka CM, Giacomel MC, Araújo MR, et al. Immunoexpression of IGF1, IGF2, and osteopontin in craniofacial bone repair associated with autogenous grafting in rat models treated with alendronate sodium. Clin Oral Invest.2016;21(5):1895-903. do: 10.1007/s00784016-1975-0

10. Jonasson TH,Zancan R, Oliveira Azevedo L, Fonseca AC, Silva MCD, Giovanini $A F$, etal. Effects of low-level laser therapy and platelet concentrate on bone repair: Histological, histomorphometric, immunohistochemical, and radiographic study. JCraniomaxillofac Surg. 2017 Nov;45(11):1846-1853. doi: 10.1016/j.jcms.2017.08.008

11. Bosemark P, Isaksson H, McDonald MM, Little DG, Tägil M. Augmentation of autologous bone graft by a combination of bone morphogenic protein and bisphosphonate increased both callus volume and strength. Acta 0rthop. 2013 Feb;84(1):106-11. doi:10.3109/17453674.2013.773123.

12. Altundal $H, G$ Gursoy $B$. The influence of alendronate on bone formation after autogenous free bone grafting in rats. Oral Surg Oral Med Oral Pathol Oral Radiol Endod. 2005; 99(3):285-91.

13. Von Knoch F, Jaquiery C, Kowalsky M. Effects of bisphosphonates on proliferation and osteoblast differentiation of human bone marrow stromal cells. Biomaterials. 2005;26(34):6941-49.

14. Camati PR, Giovanini AF, Peixoto HEM, Schuanka CM, Giacomel MC, Araújo MR, et al. Immunoexpression of IGF1, IGF2, and osteopontin in craniofacial bone repair associated with autogenous grafting in rat models treated with alendronate sodium. Clin Oral Investig.2017 Jun;21(5):1895-1903. do: 10.1007/ s00784-016-1975-0.
15. Yaffe A, Kollerman R,Bahar H, Binderman I. The influence of alendronate on bone formation and resorption in a rat ectopic bone development model.J Periodontol. 2003; 74(1):44-50. doi: 10.1902/jop.2003.74.1.44

16. Myoung H, Park JY, Choung PH. Effects of a bisphosphonate on the expression of bone specific genes after autogenous free bone grafting in rats. J Periodontal Res. 2001; 36(4):244-51.

17. Tatli U,Üstün Y,Kürkçü M, Benlidayı ME. Effects of zoledronic acid on physiologic bone remodeling of condylar part of TMJ:A radiologic and histomorphometric examination in rabbits. ScientificWorldJournal. 2014 Jan 21:2014:649026. doi:10.1155/2014/649026.

18. Naidu A, Dechow PC, Spears R, Wright JM, Kessler HP,Opperman LA. The effects of bisphosphonates on osteoblasts in vitro. Oral Surg Oral Med Oral Pathol Oral Radiol Endod. 2008;106(1):829-37.

19. Nishikawa M, Akatsu T, Katayama Y. Bisphosphonates act on osteoblastic cell and inhibit osteoclast formation in mouse marrow cultures. Bone. 1996;18:9-14.

20. Renholtz GG, GetzB, Pederson L. Bisphosphonates directly regulate cell proliferation, differentiation, and gene expression in human osteoblasts. Cancer Res. 2000;60:6001-7.

21. AmanatN,McDonald M, Godfrey C, Bilston L. Little D. Optimal timing of a single dose of zolendronic acid to increase strength in rat fracture repair. J of Bone and Mineral Res. 2007;22(6);867-76.

22. Jabbour Z,El-Hakim M, Henderson JE, de Albuquerque RF Jr. Bisphosphonates inhibit bone remodeling in the jaw bones of rats and delay healing following tooth extractions. Oral Oncol. 2014;50(5):485-90.

23. Ashwinirani SR, Suragimath G, Jaishankar HP, Kulkarni P,Biijaragi SC, Sangle VA.Comparison of diagnostic accuracy of conventional intraoral periapical and direct digital radiographs in detecting interdental bone loss. J Clin Diagn Res. 2005; 9(2):ZC35-8

24. Kawat;a T, Tenjou K, Tokimasa C. Effect of Alendronate on osteoclast differentiation and bone volume in transplanted bone. Exp Anim. 2004; 53(1):47-51.

Melissa Rodrigues De Araujo (Corresponding address)

Address: Av. Pref. Lothário Meissner, 632, Jardim Botânico 80210-170, Curitiba, Paraná, Brazil

Email: melissararaujo@hotmail.com

Date submitted: 2019 Mar 03

Accept submission: 2019 Aug 26 